\title{
Rubia cordifolia L. and Glycyrrhiza glabra L. Medicinal Plants as Potential Source of COX-2 Inhibitors
}

\author{
Prabhjit Kaur $^{\mathrm{a}}$, Satwinderjeet Kaur ${ }^{\mathrm{a} *}$, Subodh Kumar ${ }^{\mathrm{b}}$ and Palwinder Singh ${ }^{\mathrm{b}}$ \\ ${ }^{a}$ Department of Botanical \& Environmental Sciences, Guru Nanak Dev University, Amritsar-143005, Punjab, India \\ ${ }^{\mathrm{b}}$ Department of Chemistry, Guru Nanak Dev University, Amritsar-143005, Punjab, India. \\ *Corresponding author \\ Dr. Satwinderjeet Kaur (Reader) \\ Department of Botanical and Environmental Sciences, \\ Guru Nanak Dev University, \\ Amritsar-143005, (Punjab) India \\ Tel. No.: 91-183-2259732,2451048 \\ Fax: 91-183-2258819, 20 \\ sjkaur@rediffmail.com; sjkaur2001@yahoo.co.in \\ Received: 28 June 2009; | Revised: 16 August 2009; | Accepted: 15 December 2009

\section{Abstract} \\ The association of chronic inflammation with development of human cancer is well recognized. \\ There are number of reports of involvement of inflammatory process in the initiation and progress of cancer. \\ The search for selective inhibitors of Cyclooxygenase-2 isoenzymes and that too from natural origin is \\ considerably important. Rubia cordifolia L. and Glycyrrhiza glabra L. find an important place in the \\ Ayurvedic system of medicine. Several secondary plant metabolites were isolated from roots of $R$. cordifolia \\ and rhizomes of G. glabra and were investigated for the COX-2 inhibitory activity using Cayman COX \\ (ovine) inhibitory screening assay. A few molecules showed potent COX-2 inhibitory activity which may \\ serve as lead molecules for cancer chemoprevention studies.
}

Keywords: Cancer chemoprevention; Rubia cordifolia; Glycyrrhiza glabra; phytochemicals;

COX-2 inhibitors.

\section{Introduction}

Chronic inflammation induced by biological, chemical and physical factors has been associated with increased risk of human cancer at various sites $[1,2]$. Autoimmune and inflammatory reactions of uncertain etiology (e.g. ulcerative colitis, pancreatitis etc.) are also associated with increased risk of cancer. There are multiple lines of evidence of an association between inflammatory tissue damage and the development of cancer [3]. In general, longer the inflammation persists, the higher the risk of cancer. Inflammation is a step by step process that includes injury, repair and resolution. All inflammatory cells (neutrophils, monocytes, 
macrophages, eosinophils, dendritic cells, mast cells and lymphocytes) are recruited after damage or an infection and may contribute to the onset and progression of cancer. Key molecular players that link inflammation to genetic alterations are prostaglandins, cytokines, nuclear factor $\mathrm{NF \kappa B}$, chemokines and angiogenic factor [4]. Recent research has shown that increased amount of prostaglandin $\mathrm{E}_{2}$ in both human and experimental tumors inhibit host immunity and may play an important role in carcinogenesis [5]. Cyclooxygenase (COX-2), an important enzyme involved in mediating the inflammatory process produces $\mathrm{PGE}_{2}$ from endogenous arachidonic acid [6]. Several isoforms of COX have been reported. COX-1, the constitutive isoenzyme that is expressed in most tissues, controls homeostasis by maintaining the physiological level of prostaglandins. COX-2 is inducible and dramatically up-regulated by a wide variety of stimuli such as cytokines, mitogens, oncogenes, growth factor and tumor promoters and is detectable in only certain types of tissues [3, 7]. Elevated levels of $\mathrm{PGE}_{2}$ and enhanced COX-2 activity are frequently observed in a variety of malignancies, including those of the breast, prostate, bladder, liver, pancreas, skin, lung, colon and brain $[8,9,10]$. Therefore, the suppression of prostaglandin synthesis through the selective inhibition of COX-2 is now regarded as a promising and practical approach to cancer prevention. COX inhibitors such as celecoxib, piroxicam, sulindac and aspirin have been shown to reduce the formation and growth of experimentally induced cancer in animals $[11,12$, 13]. A concern relevant to the use of COX-2 inhibitors is also associated with adverse side effects that recently resulted in the withdrawl of Vioxx and Celebrax that were being investigated as potential cancer chemopreventive agents [14, 15]. The major reasons for the side effects were related to high doses of these agents and it was generally concluded that COX-2 inhibitors induce cardiovascular problems when prescribed at high doses over long durations [16].

The COX-2 inhibitors can also inhibit COX-1 as well. This is problematic because COX-1 inhibition 'turns off' some important functions such as the repair and maintenance of stomach lining, which result in varying degrees of gastric ulcerations, perforation or obstructions [17]. So, there is a need of drugs which inhibit COX-2 without affecting $\mathrm{COX}-1$ (selective $\mathrm{COX}-2$ inhibitors). Selective COX-2 inhibitors hold promise for cancer chemoprevention. More recently, human clinical trials with COX-2 inhibitor drugs have shown similar antiinflammatory and analgesic efficacy to traditional NSAIDs with significantly less gastrotoxicity [18]. However, these products offer some advantage in terms of side effects but they are nine times more expensive on a daily dose comparison [19]. Fortunately, there is now some evidence that natural COX-2 inhibitors may obstruct the production of pain and inflammation and do so in a more gentle manner and for less money. Baumann and coworkers were the first to report in a study that some dietary polyphenols inhibit arachidonic acid peroxidation [20]. Since then several researches have reported that many dietary polyphenols possess COX-2 inhibitory or stimulatory effects $[21,22,23]$. COX inhibition by polyphenols may account for anti-inflammatory effects, which reduce prostaglandin synthesis. Therefore, it should be noted that the concurrent use of polyphenols and NSAIDs could be beneficial or deleterious and thus necessitates constant attention by healthcare providers.

We have been testing different classes of synthetic compounds and their derivatives for COX-2 inhibitory activities [24, 25, 26] besides evaluating antimutagenic/antigenotoxic activity of polyphenolic extract/fractions isolated from Ayurvedic medicinal plants [27-34]. In the present study, it was planned to evaluate the COX-2 inhibitory potential of various polyphenols and related compounds (natural plant products) isolated from medicinal plants viz. $R$. cordifolia and G. glabra.

\section{Materials and methods}

The roots of $R$. cordifolia and G. glabra were purchased from a local market at Amritsar, India. Voucher specimens No. 0342-B-03/2006 (R. cordifolia) and 0342-A-03/2006 (G. glabra) have been kept in the herbarium of the Department of Botanical and Environmental Sciences, Guru

C 2010 by NWPII. All rights reserved. 
Nanak Dev University, Amritsar, Punjab, India. Plant material were washed with tap water, dried at $40^{\circ} \mathrm{C}$ and crushed to make powder. The bioassay kit was purchased from Cayman Chemicals.

\subsection{Isolation of Phytochemicals}

The powdered roots of $R$. cordifolia and rhizomes of G.glabra were percolated with $80 \%$ methanol to obtain the methanol extract. The methanol extract was further fractionated with a series of organic solvents to obtain respective fractions. The various molecules were isolated as per Flow chart I, IIa and IIb. Structure elucidation of the isolated molecules was done using Nuclear Magnetic Resonance and Mass spectroscopic techniques.

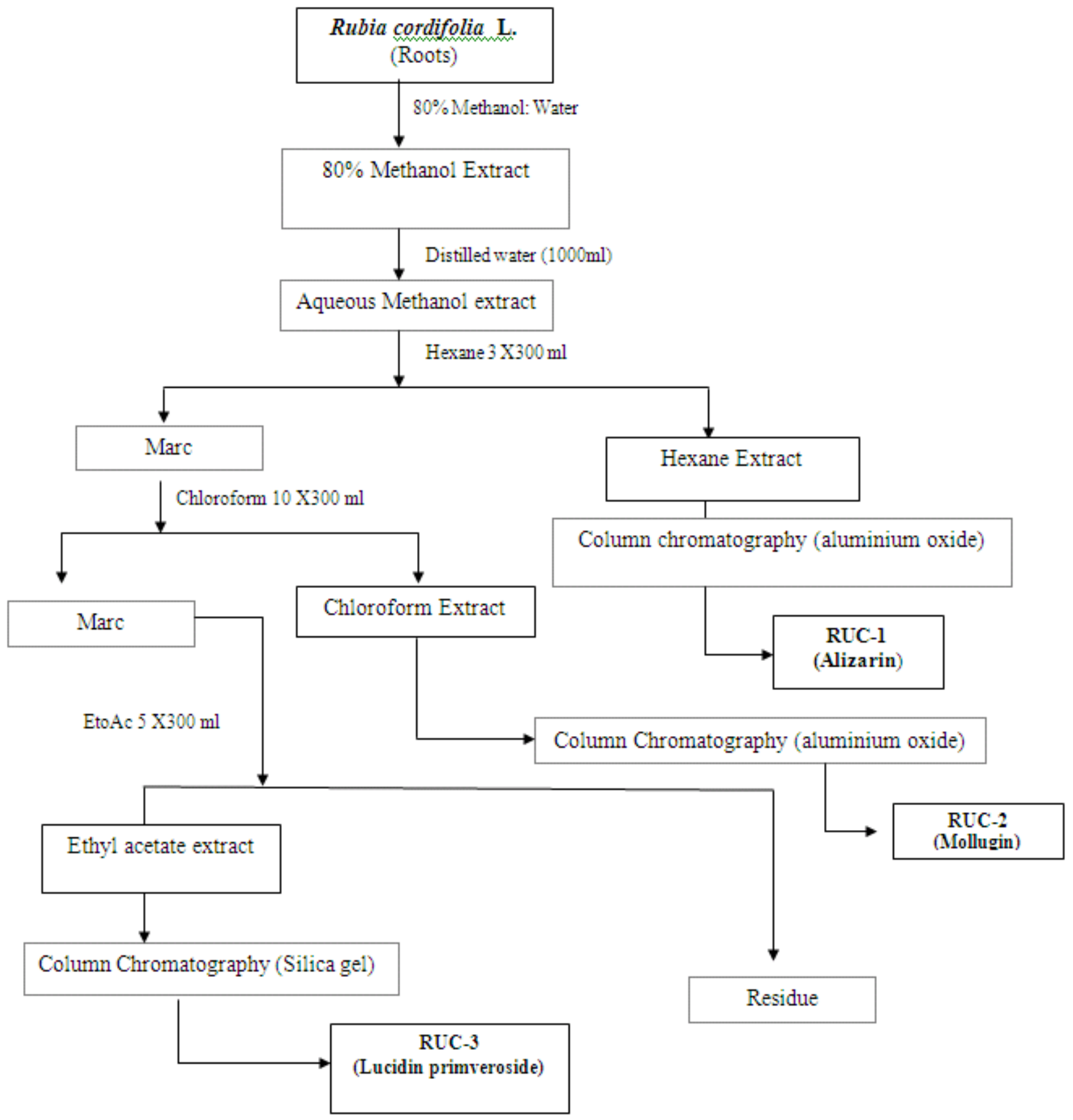

Flow Chart I: Isolation of phytochemicals from Rubia cordifolia L. 


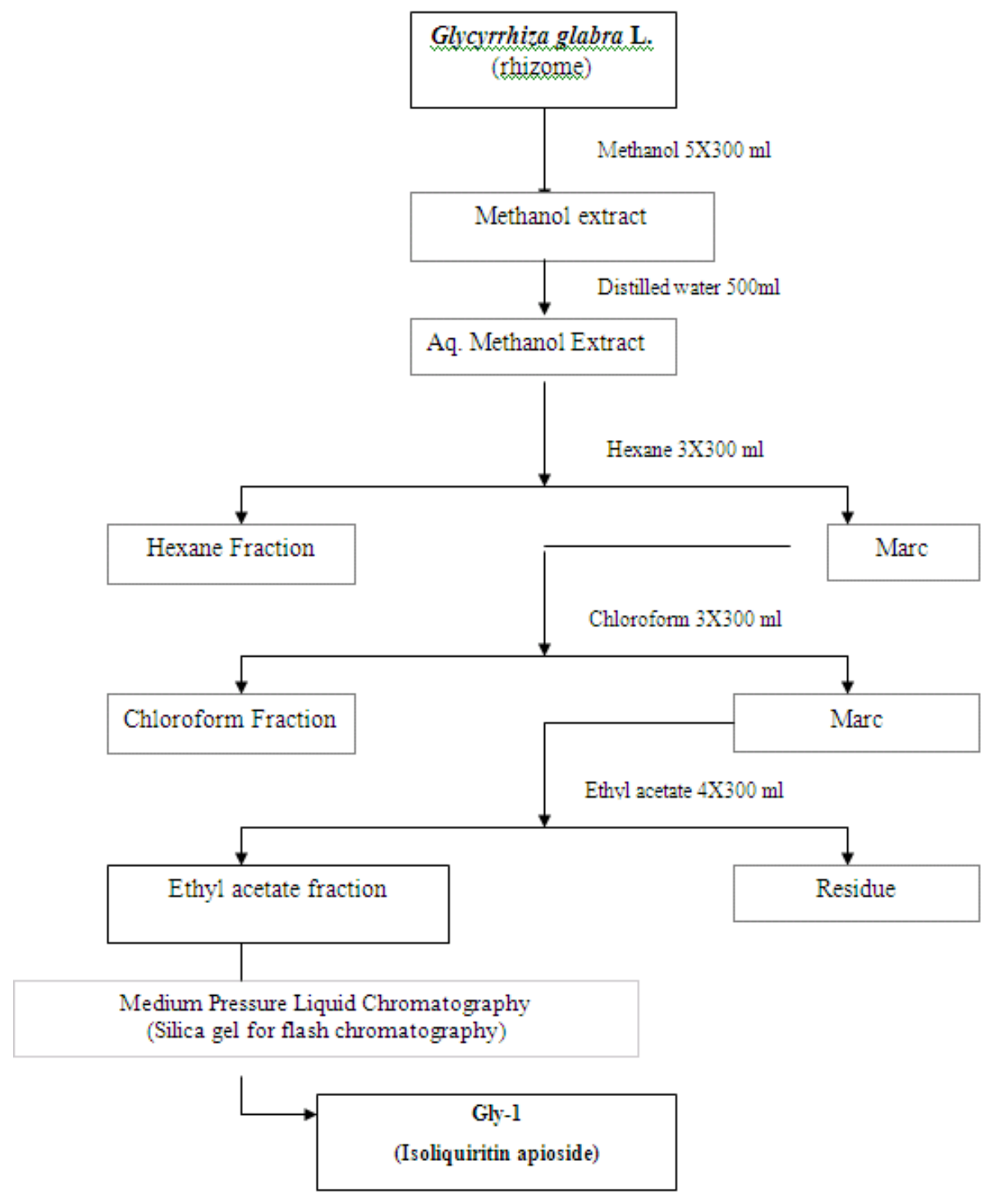

Flow Chart IIa: Isolation of phytochemicals from Glycyrrhiza glabra $L$.

\subsection{COX-2 inhibitory activity}

In vitro COX-2 inhibiting activities of the compounds have been evaluated using ' $\mathrm{COX}$ (ovine) inhibitor screening assay' kit with 96-well plates. Both ovine COX-1 and COX-2 enzymes were included. This screening assay directly measures $\mathrm{PGF}_{2 \alpha}$ produced by $\mathrm{SnCl}_{2}$ reduction of COX-derived $\mathrm{PGH}_{2}$. $\mathrm{COX}-1, \mathrm{COX}-2$, initial activity tubes were prepared taking $950 \mu \mathrm{l}$ of reaction buffer, $10 \mu \mathrm{l}$ of heme and $10 \mu \mathrm{l}$ of COX-1 and COX-2 enzymes in respective tubes. Similarly, COX-1, COX-2 inhibitor tubes were prepared by adding $20 \mu \mathrm{l}$ of inhibitor (compound under test) in each tube in addition to the above ingredients. The background tubes correspond to inactivated COX-1 and COX-2 enzymes obtained after keeping the tubes containing enzymes in boiling water for $3 \mathrm{~min}$. along with vehicle 
control. Reactions were initiated by adding $10 \mu \mathrm{l}$ of arachidonic acid in each tube and quenched with $50 \mu \mathrm{l}$ of $\mathrm{IM} \mathrm{HCl} . \mathrm{PGH}_{2}$ thus formed was reduced to $\mathrm{PGF}_{2 \alpha}$ by adding $100 \mu \mathrm{l} \mathrm{SnCl}_{2}$. The prostaglandin produced in each well was quantified using broadly specific prostaglandin antiserum that binds with major prostaglandins and reading the $96-w e l l$ plate at $405 \mathrm{~nm}$. The wells of the 96-well plate showing low absorption at $405 \mathrm{~nm}$ indicated the low level of prostaglandins in these wells and hence the less activity of the enzyme. Therefore, the COX inhibitory activities of the compounds could be quantified from the absorption values of different wells of the 96-well plate.

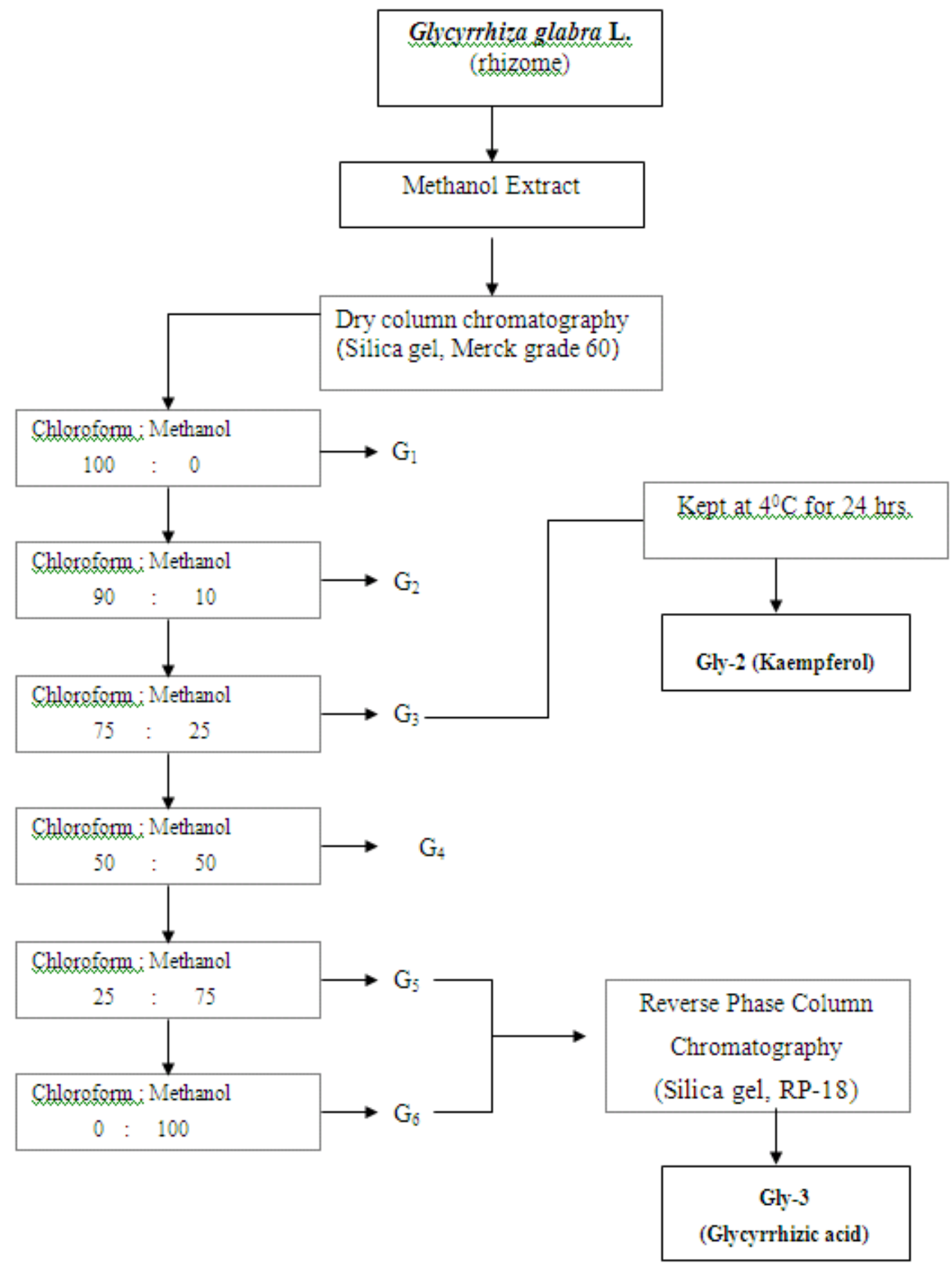

Flow chart IIb: Isolation of phytochemicals from Glycyrrhiza glabra $L$. 
Table 1: In vitro percentage inhibition and $\mathrm{IC}_{50}$ values for $\mathrm{COX}-1$ and $\mathrm{COX}-2$ enzymes by phytochemicals isolated from $R$. cordifolia $\mathrm{L}$.

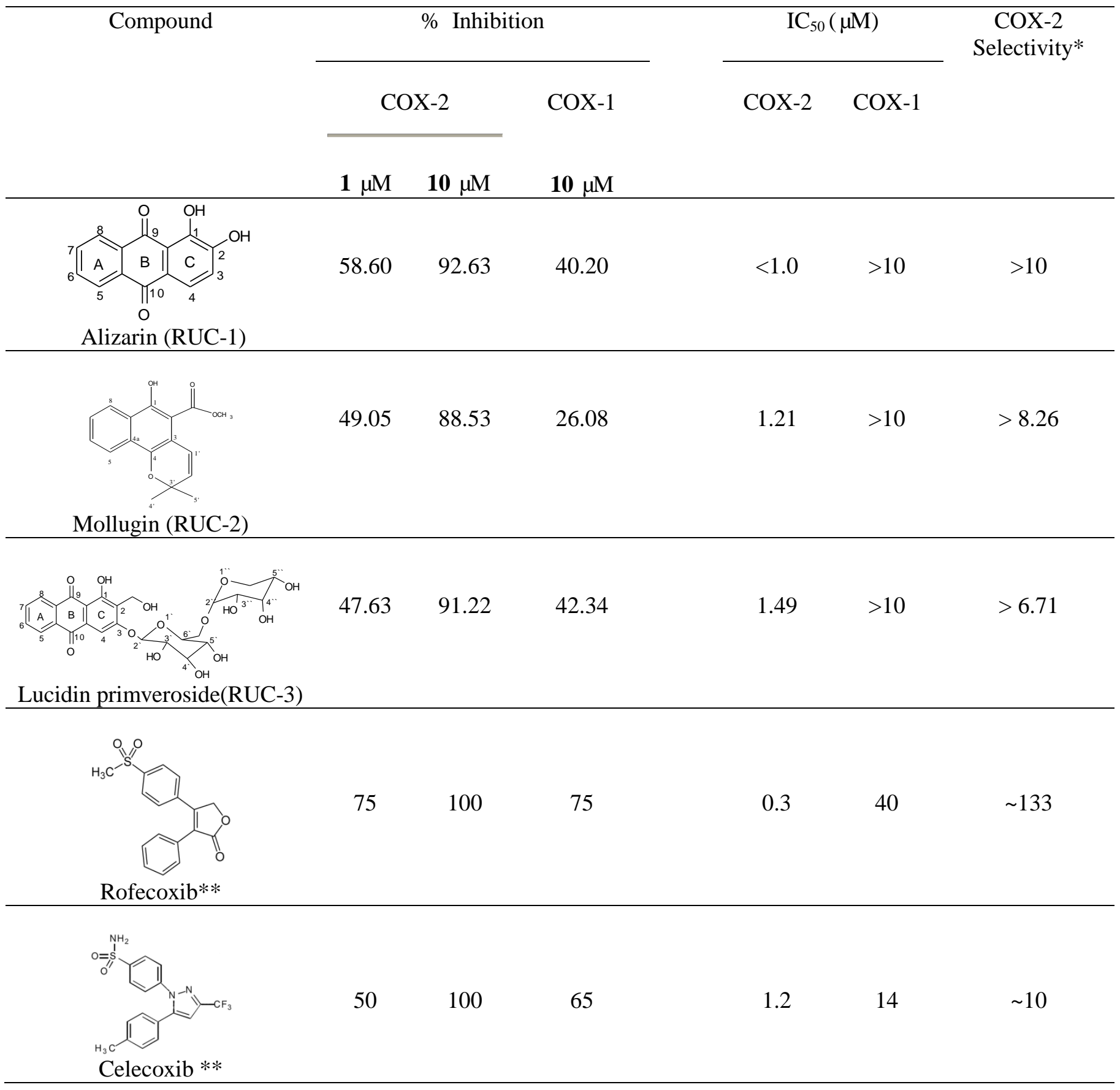

**Reported in literature [63].

$* \mathrm{COX}-2$ selectivity $=\mathrm{IC}_{50}(\mathrm{COX}-1) / \mathrm{IC}_{50}(\mathrm{COX}-2)$ 
Table 2: In vitro percentage inhibition and $\mathrm{IC}_{50}$ value for $\mathrm{COX}-1$ and $\mathrm{COX}-2$ enzymes by phytochemicals of G. glabra L.

Compound

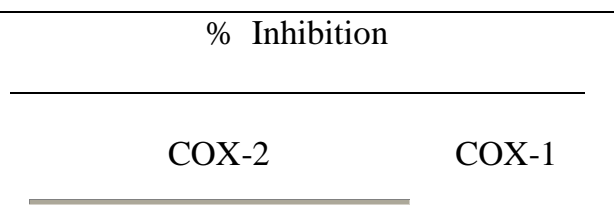

$\frac{\mathrm{IC}_{50}(\mu \mathrm{M})}{\mathrm{COX}^{2} \quad \mathrm{COX}-1}$

COX-2

Selectivity*

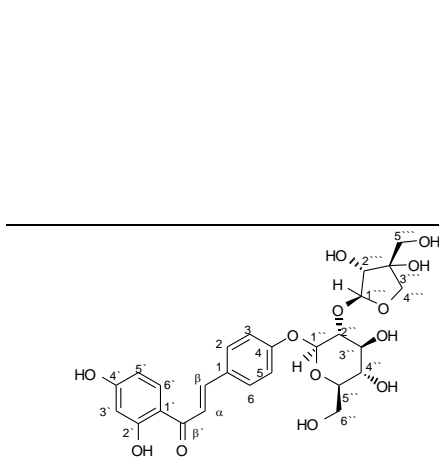

Isoliquiritin apioside(Gly-1)

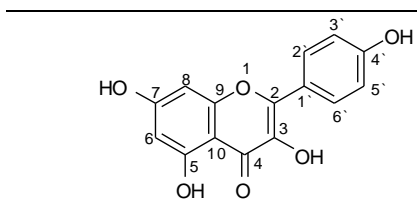

57.2

$1 \mu \mathrm{M} \quad 10 \mu \mathrm{M}$

$10 \mu \mathrm{M}$

Kaempferol(Gly-2)

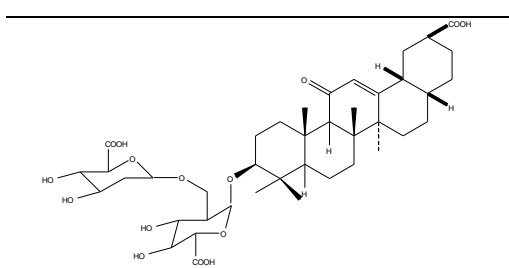

51.94

97.08

64.24

$<1.0$

$<10$

$<10$

Glycyrrhizic acid(Gly-3)

72.60

95.08

18.66

$<1.0$

$>10$

$>10$

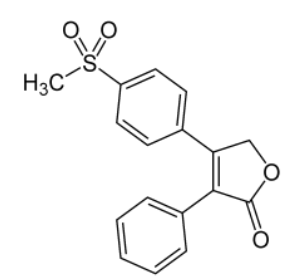

Rofecoxib**

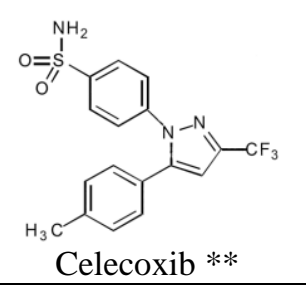

75

100

75

0.3

40

$\sim 133$

***Reported in literature [63].

$* \mathrm{COX}-2$ selectivity $=\mathrm{IC}_{50}(\mathrm{COX}-1) / \mathrm{IC}_{50}(\mathrm{COX}-2)$ 


\section{Results}

Some phytoconstituents isolated from $R$. cordifolia and G. glabra showed promising results as selective COX-2 inhibitors.

\subsection{Rubia cordifolia $\mathbf{L}$.}

As seen from Table 1 Alizarin (RUC-1) was found to be the most selective inhibitor of COX-2 (COX-2 selectivity >10) among the compounds isolated from R.cordifolia. At a concentration of $10 \mu \mathrm{M}$, it inhibited the COX-1 by $40.20 \%$ whereas COX-2 was inhibited by $92.63 \%$. Mollugin (RUC-2) inhibited the COX-2 by $88.53 \%$ at concentration of $10 \mu \mathrm{M}$ in comparison to inhibition of COX-1 by $26.08 \%$. It showed COX-2 selectivity >8.26. Lucidin primveroside (RUC-3) also inhibited COX-2 (COX-2 selectivity >6.71) It showed $42.34 \%$ inhibition of COX-1 at concentration of $10 \mu \mathrm{M}$ and inhibited the COX-2 by $91.22 \%$ at the same concentration.

\subsection{Glycyrrhiza glabra L.}

Isoliquiritin apioside (Gly-1) showed $89.03 \%$ inhibition of $\mathrm{COX}-2$ at $10 \mu \mathrm{M}$ and $62.74 \%$ of COX-1. The molecule showed COX-2 selectivity less than 10. Kaempferol (Gly-2) inhibited COX-2 by $97.08 \%$ at a concentration of $10 \mu \mathrm{M}$ in comparison to COX-1 by $64.24 \%$. It showed COX-2 selectivity less than 10 (Table 2). Glycyrrhizic acid (Gly-3) was found to be most selective inhibitor of COX-2 amongst the phytochemicals isolated from G.glabra. At a concentration of $10 \mu \mathrm{M}$, it inhibited the activity of COX-2 by $95.08 \%$ as compared to COX-1 which was inhibited by $18.66 \%$. It showed COX-2 selectivity more than 10 (Table 2 ).

\section{Discussion}

Carcinogenesis is a long and multistep process that include initiation, promotion and progression [35]. Initiation is a result of rapid and irreparable assault to the cell. Causes of cancer initiation include oxidative stress, chronic inflammation [36] and genotoxic damage by carcinogen [37]. DNA damage can result in arrest or induction of transcription, induction of signal transduction pathways, replication errors and genomic instability, all processes associated with carcinogenesis [38]. COX-2, the inducible form of cyclooxygenase that catalyse the rate-limiting steps in prostaglandin synthesis from arachidonic acid, plays an important role in cancer. Several lines of evidence indicate the initial role of COX-2 in carcinogenesis as a well-established tumor promoter [39]. Over expression of COX-2 leads to malignant cell proliferation and invasion and this effect is reversed by non-steroidal antiinflammatory agents elucidating the importance of COX-2 inhibitors in cancer chemoprevention [40].

Although there are various drugs as COX-2 inhibitors are available in the market but due to their adverse side effects, continuous withdrawal of these drugs takes place from time to time. There is utmost need to search for the natural selective COX-2 inhibitors (mainly of dietary origin) as these are regarded as safe.

Polyphenols are one such class of molecules which vary from simple structures to complex ones and may act as NSAIDs like compounds [41] and this activity appeared to be related to their phenol function [42]. Mollugin (napthaquinone), Alizarin (anthraquinone) and Lucidin primveroside (anthraquinone glycoside) were isolated from $R$. cordifolia. These molecules are of much interest as cancer chemopreventive agents. However, they have been very less explored for COX-2 inhibitory activity. The present investigation showed that mollugin (RUC2), selectively inhibited COX-2. This is in consistence with the report of Oku and Ishiguro that 1, 4-napthaquinones (impatienolate and balsaminolate) isolated from Impatiens balsamina L. showed selective COX-2 inhibitory activities [43]. Napthaquinone derivatives, furonapthaquinone and $\beta$-Lapachone were also shown to exhibit selective inhibition of COX-2 [44, 45]. Shikonin, another napthaquinone derivative has been reported as a potent inhibitor of prostaglandin $\mathrm{E}_{2}$ [46]. The cyclooxygenase inhibitory activity of anthraquinone molecules Alizarin (RUC-1) and Lucidin primveroside (RUC-3) is in concordance with the various reports that anthraquinone derivatives can inhibit cyclooxygenases. Anthraquinone rich extracts of Aloe vera gel possess anti-inflammatory activity by inhibiting the arachidonic acid pathway via
(C) 2010 by NWPII. All rights reserved. 
inhibition of cyclooxygenases [47]. Recently, Gan and coworkers reported that 3alkylaminopropoxy-9,10-anthraquinone derivatives interfere with the conversion of arachidonic acid to prostaglandin $\left(\mathrm{PGH}_{2}\right)$ [48].

Among the molecules isolated from G.glabra, Glycyrrhizic acid (Gly-3) (triterpene glycoside) was the most potent in inhibiting the $\mathrm{COX}-2$ activity. It showed strong inhibition of COX-2 as compared with COX-1. Triterpenes isolated from aerial parts of Aralia cordata possess COX-2 inhibitory activity [49]. Asiatic acid, a triterpene isolated from leaves of Centella asiatica inhibited the nitric oxide and prostaglandin $\mathrm{E}_{2}$ production in RAW 264.7 macrophage cells [50]. Triterpenes isolated from Eriobotrya japonica prevent pulmonary inflammatory diseases by inhibiting iNOS, COX-2 and cytokines (TNF-alpha, IL-Ibeta and IL-8) production in human lung epithelial cells (A-549) [51]. Kaempferol (Gly-2) isolated from G.glabra also showed moderate selectivity for COX-2. Flavonoids are the well studied class of polyphenols as COX-2 inhibitors. Kaempferol and its derivatives isolated from seeds of Prunus tomentosa exhibited inhibitory activities on nitric oxide (NO) and prostaglandin $\mathrm{E}_{2}$ (COX-2) production [52]. Kaempferol and quercetin exhibited anti-inflammatory activities by inhibiting iNOS and COX-2 protein levels in cultured human umbilical vein endothelial cells [53]. Luteolin and galangin, well known flavonoid molecules were studied as first dietary polyphenols as inhibitors of arachidonic acid peroxidation [20]. After this Chrysin and luteolin were considered as potent anti-inflammatory agents as they effectively suppressed COX-2 activity [54]. In 2008, Li and coworkers [55] reported that a new molecule Malsudone along with known flavonoids luteolin, isoquercetin, 7methoxyflavone and luteolin-7-O--glycoside possess potent inhibitory effect on COX-2 with moderate inhibition of COX-1. Quercetin was demonstrated to protect against colon cancer by suppressing the expression of proinflammatory mediators (COX-1, COX-2, iNOS) [56]. Kolaviron, isolated from seeds of Garcinia kola has been reported to possess anti-inflammatory activities by inhibiting COX-2 and iNOS expression through down regulation of NF-Kappa
B and AP-1 DNA binding activity [57]. Isoliquiritin apioside (Gly-1) a chalcone glycoside also showed good activity as COX-2 inhibitor. Certain reports show that chalcones and its derivatives also possess the potential to inhibit COX-2 [58]. Some chalcone derivatives were shown to be potent and selective COX-2 inhibitors [59]. Isoliquiritigenin isolated from roots of Glycyrrhiza uralensis [60] and Cardamnin, isolated from the fruits of Alpinia rafflesiana [61] inhibited COX-2 and iNOS expression in RAW 264.7 macrophage cells.

Among the phytochemicals tested from the medicinal plants, the percentage inhibition and $\mathrm{IC}_{50}$ values of 'RUC-1' 'RUC-2' from $R$. cordifolia and 'Gly-3' from G. glabra are in between that of corresponding reported values of Rofecoxib and Celecoxib. The natural origin and moderate selectivity of these compounds for COX-2 in comparison to rofecoxib may also make them better substitutes of Rofecoxib and Celecoxib as their too much selectivity for COX-2 leads to the cardiac toxicity. Studies carried out in our laboratory have also shown these molecules to possess antigenotoxic activity against $\mathrm{H}_{2} \mathrm{O}_{2}$ and 4NQO in SOS chromotest using E. coli PQ37 and in Comet assay using human blood lymphocytes $[32,62]$.

The chemopreventive effects of various phytochemicals have often been associated with their anti-inflammatory activities especially due to the inhibition of COX-2. Since the isolated phytochemicals showed potent COX-2 inhibitory activity these may serve as potential candidates for chemopreventive/chemotherapeutic studies.

\section{Acknowledgements}

The authors are thankful to the Department of Science and Technology (DST), New Delhi (India) for funding the research project.

\section{References}

1. Ohshima, H.; Bartsch, H. Chronic infections and inflammatory processes as cancer risk factors: possible role of nitric oxide in carcinogenesis, Mutation Research, 1994, 305, 253-264.

(C) 2010 by NWPII. All rights reserved. 
2. Ohshima, H.; Tatemichi, M.; Sawa, T. Chemical basis of inflammation-induced carcinogenesis, Archives of Biochemistry and Biophysics, 2003, 417, 3-11.

3. Prescott, S. M.; Fitzpatrick, F. A. Cyclooxygenase-2 and carcinogenesis, Biochimica Biophysica acta, 2000, 1470, M69-78.

4. Federico, A.; Marqillo, F.; Tuccillo, C.; Ciardiello, F.; Loqquercio, C. Chronic inflammation and oxidative stress in human carcinogenesis, International Journal of Cancer, 2007, 121, 2381-2386.

5. Dubois, R.N.; Abramson, S.B.; Crofford, L.; Gupta, R.A.; Simon, L.S.; Van De Putte, L.B.; Lipsky, P.E. Cyclooxygenase in biology and disease, FASEB Journal, 1998, 12, 1063-1073.

6. Funk, C.D.; Funk, L.B.; Kennedy, M.E.; Pong, A.S.; Fitzgerald, G.A. Human platelet/erythroleukemia cell prostaglandin G/H synthase: cDNA cloning, expression and gene chromosomal assignment, FASEB Journal, 1991, 5, 2304-2312.

7. Gately, S. The contributions of cyclooxygenase-2 to tumor angiogenesis, Cancer Metastasis Reviews, 2000, 19, 19-27.

8. Ristimaki, A.; Sivula, A.; Lundin, J.; Lundin, M.; Salminen, T.; Haglund, C.; Joensuu, H.; Isola, J. Prognostic significance of elevated cyclooxygenase- 2 expression in breast cancer, Cancer Research, 2002, 62, 632-635.

9. Khuri, F.R.; Wu, H.; Lee, J.J.; Kemp, B.L.; Lotan, R.; Lippman, S.M.; Feng, L.; Hong, W.K.; Xu, X.C. Cyclooxygenase -2 overexpression is a marker of poor prognosis in stage 1 non-small cell lung cancer, Clinical Cancer Research, 2001, 7, 861-867.

10. Turini, M.E.; DuBois, R.N. Cyclooxygenase-2: a therapeutic target, Annual Review of Medicine, 2002, 53, 35-57.

11. Earnest, D.L.; Hixson, L.J.; Alberts, D.S. Piroxicam and other cyclooxygenase inhibitors: potential for cancer chemoprevention, Journal of Cellular Biochemistry Supplement, 1992, 161, 156-166.

12. Aas, A.T.; Tonnessen, T.I.; Brun, A.; Salford, L.G. Growth inhibition of rat glioma cells in vitro and in vivo by asprin, Journal of NeuroOncology, 1995, 24, 171-180.
13. Zhang, X.; Chen, Z.G.; Choe, M.S.; Lin, Y.; Sun, S.Y.; Wieand, H.S.; Shin, H.J.; Chen, A.; Khuri, F.R.; Shin, D.M. Tumor growth inhibition by simultaneously blocking epidermal growth factor receptor and cyclooxygenase-2 in a xenograft model, Clinical Cancer Research, 2005, 11, 62616269.

14. Spektor, G.; Fuster, V. Cyclooxygenase-2 inhibitors and cardiovascular risk-where are we now? Nature Clinical Practice, Cardiovascular Medicine, 2005, 2, 290-300.

15. Ulrich, C.M.; Bigler, J.; Potter, J.D. Nonsteroidal anti-inflammatory drugs for cancer prevention: promise, perils and pharmacogenetics, Nature Reviews Cancer, 2006, 6, 130-140.

16. Brophy, J.M. Celocoxib and cardiovascular risks, Expert Opinion on Drug Safety, 2005, 4, 1005-1015.

17. Fries, J. Towards an understanging of NSAIDrelated adverse events: the contribution of longitudinal data. Scandinavian Journal of Rheumatology, Supplement, 1996, 102, 3-8.

18. Simon, L. S.; Weaver, A. L.; Graham, D. Y.; Kivitz, A. J.; Lipsky, P. E.; Hubbard, R. C.; Isakson, P. C.; Verburg, K. M.; Yu, S. S.; Zhao, W.W.; Geis, G. S. Anti-inflammatory and upper gastrointestinal effects of celecoxib in rheumatoid arthritis: a randomized controlled trial, The Journal of the American Medical Association, 1999, 282, 1921-1928.

19. Peterson, W.L.; Cryer, B. COX-1-sparing NSAIDs--is the enthusiasm justified? The Journal of the American Medical Association, 1999, 282, 1961-1963.

20. Baumann, J.; Von Bruchhausen, F.; Wurm, G. Flavonoids and related compounds as inhibitors of arachidonic acid peroxidation, Prostaglandins, 1980, 20, 627-639.

21. Subbaramaiah, K.; Chung, W.J.; Michaluart, P.; Telang, N.; Tanabe, T.; Inoue, H.; Jang, M.; Pezzuto, J.M.; Dannenberg, A.J. Resveratrol inhibits cyclooxygenase-2 transcription and activity in phorbol estertreated human mammary epithelial cells, Journal of Biological Chemistry, 1998, 273: 21875-21882. 
22. Goel, A.; Boland, C.R.; Chauhan, D.P. Specific inhibition of cyclooxygenase-2 (COX-2) expression by dietary curcumin in HT-29 human colon cancer cells, Cancer Letters, 2001, 172, 111-118.

23. Luceri, C.; Caderni, G.; Sanna, A.; Dolara, P. Red wine and black tea polyphenols modulate the expression of cyclooxygenase-2, inducible nitric oxide synthase and glutathione-related enzymes in azoxymethane-induced f344 rat colon tumors. Journal of Nutition, 2002, 132, 1376-1379.

24. Singh, P.; Mittal, A.; Kaur, S.; Kumar, S. 5Substituted-2, 3-diphenyltetrahydrofurans: a new class of moderately selective COX-2 inhibitors, Bioorganic and Medicinal Chemistry, 2006, 14, 7910-7916.

25. Singh, P.; Mittal, A.; Bhardwaj, A.; Kaur, S.; Kumar, S. 1-Toluene-sulfonyl-3-[(3'-hydroxy5'-substituted)-gamma-butyrolactone]-indoles: synthesis, COX-2 inhibition and anti-cancer activities, Bioorganic and Medicinal Chemistry Letters, 2008, 18, 85-89.

26. Singh, P.; Bhardwaj, A.; Kaur, S.; Kumar, S. Design, synthesis and evaluation of tetrahydropyran based COX-1/-2 inhibitors, European Journal of Medicinal Chemistry, 2009, 44, 1278-1287.

27. Kaur, S.; Grover, I.S.; Kumar, S. Antimutagenic potential of ellagic acid isolated from Terminalia arjuna, Indian Journal of Experimental Biology, 1997, 35, 478-482.

28. Kaur, S.; Grover, I.S.; Singh, M.; Kaur, S. Antimutagenicity of hydrolyzable tannins from Terminalia chebula in Salmonella typhimurium, Mutation Research, 1998, 419, 169-179.

29. Kaur, S.J.; Grover, I.S.; Kumar, S. Modulatory effects of a tannin fraction isolated from Terminalia arjuna on the genotoxicity of mutagens in Salmonella typhimurium, Food and Chemical Toxicology, 2000, 38, 11131119.

30. Kaur, S.J.; Grover, I. S.; Kumar, S. Antimutagenic potential of extracts isolated from Terminalia arjuna, Journal of Environmental Pathology Toxicology and Oncology, 2001, 20, 9-14.
31. Kaur, S.; Arora, S.; Kaur, S.J.; Kumar, S. Bioassay-guided isolation of antimutagenic factors from fruits of Terminalia bellerica, Journal of Environmental Pathology Toxicology and Oncology, 2003, 22, 69-76.

32. Kaur, P.; Kaur, S.J.; Kumar, N.; Singh, B.; Kumar, S. Evaluation of antigenotoxic activity of isoliquiritin apioside from Glycyrrhiza glabra L., Toxicology in Vitro, 2009a, 23, 680686.

33. Scassellati-Sforzolini, G.; Villarini, L.M.; Moretti, L.M.; Marcarelli, L.M.; Pasquini, R.; Fatigoni, C. Antigenotoxic properties of Terminalia arjuna bark extracts, Journal of Environmental Pathology Toxicology and Oncology, 1999, 18, 119-125.

34. Pasquini, R.; Scassellati-Sforzolini, G.; Villarini, M.; Moretti, M.; Marcarelli, M.; Fatigoni, C.; Kaur, S.; Kumar, S.; Grover, I.S. In vitro protective effects of Terminalia arjuna bark extract against the 4-nitroquinoline- $\mathrm{N}$ oxide genotoxicity. Journal of Environmental Pathology Toxicology and Oncology, 2002, 21, 33-44.

35. Brennan, M.J. Endocrinology in cancer of the breast, Status and prospects. Americal Journal of Clinical Pathology, 1975, 64, 797-809.

36. Surh, Y.J.; Kundu, J.K.; Na, H. K.; Lee, J.S. Redox-Sensitive Transcription Factors as Prime Targets for Chemoprevention with AntiInflammatory and Antioxidative Phytochemicals, Journal of Nutrition, 2005, 135, $2993-3001 S$.

37. Lee, J.S.; Surh, Y.J. Nrf2 as a novel molecular target for chemoprevention, Cancer Letters, 2005, 224, 171-184.

38. Marnett, L.J. Oxyradicals and DNA damage. Carcinogenesis, 2000, 21, 361-370.

39. Mann, J.R.; DuBois, R.N. Cyclooxygenase-2 and gastrointestinal cancer, Journal of Cancer, 2004, 10, 145-152.

40. Claria, J.; Romano, M. Pharmacological intervention of cyclooxygenase-2 and 5lipoxygenase pathways. Impact on inflammation and cancer, Current Pharmaceutical Design, 2005, 11, 3431-3437.

41. Hirata, A.; Murakami, Y.; Atsumi, T.; Shoji, M.; Ogiwara, T.; Shibuya, K.; Ito, S.; Yokoe, I.; Fujisawa, S. Ferulic acid dimmer inhibits 
lipopolysaccharide-stimulated

cyclooxygenase- 2 expression in macrophages,

In vivo, 2005, 19, 849-853.

42. Murakami, Y.; Ito, S.; Atsumi, T.; Fujisawa, S. Theoretical prediction of the relationship between phenol function and COX-2/AP-1 inhibition for ferulic acid-related compounds, In Vivo, 2005, 19, 1039-1043.

43. Oku, H.; Ishiguro, K. Cyclooxygenase-2 inhibitory 1,4-naphthoquinones from Impatiens balsamina L., Biological and Pharmaceutical Bulletein, 2002, 25, 658-660.

44. Ahn, K.Y.; Kim, B.H.; Lee, Y.R.; Hwang, D.H.; Chung, E.Y.; Min, K.R.; Kim, Y. Dual inhibitory effects of furonapthoquinone compounds on enzyme activity and lipopolysaccharide-induced expression of cyclooxygenase-2 in macrophages, Biochemical Biophysical Research Communications, 2005, 336, 93-99.

45. Lee, J.H.; Cheong, J.; Park, Y.M.; Cho, Y.H. Down-regulation of cyclooxygenase- 2 and telomerase activity by beta-lapachone in human prostate carcinoma cells, Pharmacological Research, 2005, 51, 553560.

46. Lim, E.S.; Rhee, Y.H.; Park, M.K.; Shim, B.S.; Ahn, K.S.; Kang, H.; Yoo, H.S.; Kim, S.H. DMNQ S-64 induces apoptosis via caspase activation and cyclooxygenase-2 inhibition in human nonsmall lung cancer cells, Annals of the New York Academy of Sciences, 2007, 1095, 7-18.

47. Vazquez, B.; Avila, G.; Segura, D.; Escalante, B. Anti-inflammatory activity of extracts from Aloe vera gel, Journal of Ethnopharmacology, 1996, 55, 69-75.

48. Gan, K.H.; Teng, C.H.; Lin, H.C.; Chen, K.T.; Chen, Y.C.; Hsu, M.F.; Wang, J.P.; Teng, C.M.; Lin, C.N. Antiplatelet effect and selective binding to cyclooxygenase by molecular docking analysis of 3alkylaminopropoxy-9, 10-anthraquinone, Biological and Pharmaceutical Bulletein, 2008, 31, 1547-1551.

49. Lee, I.S.; Jin, W.; Zhang, X.; Hung, T.M.; Song, K.S.; Seong, Y.H.; Bae, K. Cytotoxic and COX-2 inhibitory constituents from the aerial parts of Aralia cordata, Archives of Pharmacal Research, 2006, 29, 548-555.

50. Yun, K.J.; Kim, J.Y.; Kim, J.B.; Lee, K.W.; Jeong, S.Y.; Park, H.J.; Jung, H.J.; Cho, Y.W.; Yun, K.; Lee, K.T. Inhibition of LPS-induced $\mathrm{NO}$ and $\mathrm{PGE}_{2}$ production by Asiatic acid via NF-KappaB inactivation in RAW 264.7 macrophages: possible involvement of the IKK and MAPK pathways, International Immunopharmacology, 2008, 8, 431-441.

51. Lee, C.H.; Wu, S.L.; Chen, J.C.; Li, C.C.; Lo, H.Y.; Cheng, W.Y.; Lin, J.G.; Chang, Y.H.; Hsiang C.Y.; Ho, T.Y. Eriobotrya japonica leaf and its triterpenes inhibited lipopolysaccharide-induced cytokines and inducible enzyme production via the nuclear factor-kappaB signaling pathway in lung epithelial cells. The American journal of Chinese medicine, 2008, 36, 1185-1198.

52. Kim, S.K.; Kim, H.J.; Choi, S.E.; Park, K.H.; Choi, H.K.; Lee, M.W. Anti-oxidative and Inhibitory activities on nitric oxide (NO) and prostaglandin $\mathrm{E}_{2}$ (COX-2) production of flavonoids from seeds of Prunus tomentosa Thunberg. Archives of Pharmacal Research, 2008, 4, 424-428.

53. Crespo, I.; García-Mediavilla, M.V.; Gutierrez, B.; Sanchez-Campos, S.; Tunon, M.J.; Gonzalez-Gallego, J.A. Comparison of the effects of kaempferol and quercetin on cytokine-induced pro-inflammatory status of cultured human endothelial cells, The British Journal of Nutrition, 2008, 100, 968-976.

54. Harris, G.K.; Qian, Y.; Leonard, S.S.; Sbarra, D.C.; Shi, X. Luteolin and chrysin differentially inhibit cyclooxygenase-2 expression and scavenge reactive oxygen species but similarly inhibit prostaglandin- $\mathrm{E}_{2}$ formation in RAW-264.7 cells, Journal of Nutrition, 2006, 136, 1517-1521.

55. Li, X.; Liu, Z.; Zhang, X.F.; Wang, L.J.; Zheng, Y.N.; Yuan, C.C.; Sun, G.Z. Isolation and characterization of phenolic compounds from the leaves of Salix matsudana, Molecules, 2008, 13, 1530-1537.

56. Warren, C.A.; Paulhill, K.J.; Davidson, L.A.; Lupton, J.R.; Taddeo, S.S.; Hong, M.Y.; Carroll, R.J.; Chapkin, R.S.; Turner, N.D. Quercetin may suppress rat aberrant crypt foci 
formation by suppressing inflammatory mediators that influence proliferation and apoptosis, Journal of Nutrition, 2009, 139, 101-105.

57. Farombi, E.O.; Shrotriya, S.; Surh, Y.J. Kolaviro inhibits dimethyl nitrosamineinduced liver injury by suppressing COX-2 and iNOS expression via NF-kappaB and AP1, Life Sciences, 2009, 84, 149-155.

58. Herencia, F.; Ferrandiz, M.L.; Ubeda, A.; Dominguez, J.N.; Charris, J.E.; Lobo, G.M.; Alcaraz, M.J. Synthesis and anti-inflammatory activity of chalcone derivatives, Bioorganic and Medicinal Chemistry Letters, 1998, 8, 1169-1174.

59. Zarghi, A.; Zebardast, T.; Hakimion, F.; Shirazi, F.H.; Rao, P.N.; Knaus, E.E. Synthesis and biological evaluation of 1, 3diphenylprop-2-en-1-ones possessing a methanesulfonamido or an azido pharmacophore as cyclooxygenase-1/-2 inhibitors, Bioorganic and Medicinal Chemistry, 2006, 14, 7044-7050.

60. Kim, J.Y.; Park, S.J.; Yun, K.J.; Cho, Y.W.; Park, H.J.; Lee, K.T. Isoliquiritigenin isolated from the roots of Glycyrrhiza uralensis inhibits LPS-induced iNOS and COX-2 expression via the attenuation of NF-kappaB in RAW 264.7 macrophages, European Journal of Pharmacology, 2008, 584, 175-184.

61. Israf, D.A.; Khaizurin, T.A.; Syahida, A.; Lajis, N.H.; Khozirah, S. Cardamonin inhibits COX and iNOS expression via inhibition of p65NF-kappaB nuclear translocation and Ikappa-B phosphorylation in RAW264.7 macrophage cells. Molecular Immunology, 2007, 44, 673-679.

62. Kaur, P. Antigenotoxic potential of Rubia cordifolia L. and Glycyrrhiza glabra L. Ph.D. Thesis, 2009b, Guru Nanak Dev University, Amritsar.

63. Ranatunge, R.R.; Earl, R.A.; Garvey, D.S.; Janero, D.R.; Letts, L.G.; Martine, A.M.; Murthy, M.G.; Richardson, S.K.; Schwalb, D. J.; Young, D.V. \& Zamtseva, I. S. 3-(2Methoxytetrahydrofuran-2-yl) pyrazoles: a novel class of potent, selective cycloxygenase2 (Cox-2) inhibitors, Bioorganic and Medicinal Chemistry Letters, 2004, 14, 60496052. 